\title{
Synthesis, Swelling Characteristics, and Dye Adsorption Mechanism of a New Stimuli-Responsive Cationic Hydrogel
}

\author{
Yee Lin Tan, M. Rajkumar Yalini, Chin Hao Mah, Tee Wei Teo, and G. Roshan Deen
}

\section{ABSTRACT}

In this study, a new multi-stimulus cationic copolymer hydrogel was developed by bulk photo-polymerization of $N$-acryloyl- $N$ '-propyl piperazine (AcrNPP) and poly (ethylene glycol) methacrylate (PEGMA) with ethylene glycol dimethacrylate (EGDMA) as crosslinker. The effect of multiple external stimuli, concentration of monomers, and equilibrium swelling of the hydrogels was studied in detail. The gels swelled in acidic solutions due to protonation of tertiary amine in the piperazine ring, and de-swelled in basic solutions. The presence of PEGMA in the hydrogel enhanced the swelling and imparted water-responsive property, leading to disintegration at high concentration of $49.85 \%$. The hydrogel was evaluated as an adsorbent for the removal of an anionic dye, Congo red (CR) from water. The dye uptake capacity of the hydrogel increased with increase in the initial dye concentration. Interestingly, the swelling ratio of the hydrogel decreased at high dye concentration due to the formation of additional physical crosslinks within the hydrogel matrix. The dye uptake capacity of the hydrogel decreased with increasing temperature due to the negative-temperature responsive property of the hydrogel. The time-dependent adsorption data was fitted with seven kinetic models. Pseudo second-order model best described the kinetics of adsorption process, and the adsorption of CR onto the hydrogel could be very well described with phase-boundary controlled models. The adsorption was a multistep process with surface adsorption followed by intraparticle diffusion.

Keywords: Cationic hydrogels, dye adsorption mechanism, kinetic models, PEGMA.
Published Online: January 23, 2022

ISSN: $2684-4478$

DOI: 10.24018 / ejchem.2022.3.1.86

Y. L. Tan

Soft Materials Laboratory, National Institute of Education, Nanyang Technological University, Singapore.

M. R. Yalini

Soft Materials Laboratory, National Institute of Education, Nanyang Technological University, Singapore. C. H. Mah

Soft Materials Laboratory, National Institute of Education, Nanyang Technological University, Singapore. T. W. Teo

Soft Materials Laboratory, National Institute of Education, Nanyang Technological University, Singapore. G. Roshan Deen*

School of Medicine, Royal College of Surgeons in Ireland (RCSI), Medical University of Bahrain, Kingdom of Bahrain.

(e-mail: rdeen@rcsi.com)

*Corresponding Author

\section{INTRODUCTION}

In recent years, pollution of water bodies around the world by toxic industrial waste is one of the serious ecological and social concern. The use of synthetic organic dyes for coloring purposes is expanding in textile, food, plastic, and pharmaceutical industries which release a large volume of dye effluents into the environment [1]-[3]. Among these, textile industries produce a large volume of effluents containing spent synthetic dyes at various stages of dyeing the textiles. Many of these synthetic dyes are non-biodegradable and are characterized by complex chemical structures with high molar mass [4]. The presence of synthetic dyes above the tolerance limit, has detrimental effects on living organisms and the ecosystem. In terms of human health, these synthetic dyes lead to severe dysfunctions of reproductive systems, brain, kidney, and the central nervous systems [5]-[8]. Very strict laws are thus in place for the elimination of dyes from wastewater before its discharge into water bodies or land.

Treatment of industrial effluents by conventional physical and chemical methods such as flocculation [9], floatation [10], coagulation [11], precipitation [12], ion exchange [13], reverse osmosis [14], photodegradation [15], oxidation [16], sorption [17], and biological treatments [18] are currently in use. Among these methods, adsorption or sorption using activated carbon is widely used for dye removal applications due to its simplicity in design and usage, and the ability to remove a wide range of pollutants [19]. However, the use of activated carbon as adsorbents is limited due to its high cost, and therefore there is a need to develop cost-effective alternate adsorbents with sufficient adsorption capacity, and adsorption rate. A few of the alternatives are renewable raw materials [20], [21], agricultural waste [22], and low-cost synthetic inorganic and organic materials [23], [24].

Among the low-cost organic materials, synthetic functional polymeric materials have been widely used as adsorbents for the removal of pollutants such as dyes and heavy metals from wastewater. The polymeric 
adsorbents have many advantages over conventional adsorbents such as activated carbon and ion-exchange resins, such as simple processing methods, introduction of specific chemical functional groups for target specific interactions, and effective regeneration of the adsorbent under mild conditions [25], [26]. Further, polymer-based adsorbents can be developed in various architectures such as hydrogels, microgels, beads, interpenetrating networks (IPN) and surface grafted resins with well-defined physicochemical properties [27].

Hydrogels are crosslinked polymers with three-dimensional structure that can absorb and retain large amount of water or aqueous solution without undergoing dissolution. Stimuli-responsive hydrogels or smart hydrogels swell and shrink in response to changes in external stimuli (such as $\mathrm{pH}$, temperature, salt and surfactant concentration, light, and magnetic field) is an interesting class of adsorbent material [28]-[31]. During the swelling process of smart hydrogels, the expansion of polymer network allows diffusion of various molecules (dyes, metal ions) into the matrix, facilitating their removal from the external solution. In recent years, functional stimuli-responsive hydrogels containing specific functional groups have been studied as sorbents for removal of pollutants from wastewater [32]-[34]. The presence of specific functional groups in the hydrogel allows various possible interaction between the functional groups and pollutant. These materials have significant advantages over other materials in that, they can be synthesized with a wide range of physicochemical properties and with specific chemical ligands for target-specific removal of pollutants [35]-[37].

In this study, a new smart cationic copolymer hydrogel based on $\mathrm{N}$-acryloyl-N'-propyl piperazine and poly (ethylene glycol) methacrylate was synthesized by photo-polymerization in bulk and characterized. The presence of AcrNPP in the hydrogel imparted $\mathrm{pH}$ and temperature responsive properties, while PEGMA imparted water-responsive and erodible features. The dye adsorption property of the new hydrogel was studied using an anionic model dye, Congo red (CR), and the adsorption kinetics and mechanism was modeled using various kinetic models. This study allows for future design and development of erodible cationic hydrogels with tunable physicochemical properties for versatile removal of pollutants from aqueous solutions.

\section{Materials AND MethodS}

\section{A. Raw Materials}

Acrylic acid (Tokyo Chemical Industry), benzoyl chloride (Aldrich), ethylene glycol dimethacrylate (EGDMA) (Fluka), 2,2-dimethoxy-2-phenylacetophenone (DMPA) (Aldrich), $N$-propylpiperazine dihydrobromide (Alfa-Aesar), poly(ethylene glycol) methacrylate (PEGMA, $\mathrm{M}_{\mathrm{n}}=360$ ) (Aldrich), and Congo Red (Aldrich) were used as received. Deionized water was used for all aqueous sample preparations.

\section{B. Synthesis of N-acryloyl-N'-propyl piperazine (AcrNPP)}

Acryloyl chloride was prepared by reacting acrylic acid with benzoyl chloride by following the procedure reported in the literature [38]. The monomer AcrNPP was synthesized by reacting freshly prepared $\mathrm{N}$ propyl piperazine with acryloyl chloride in distilled THF at $0{ }^{\circ} \mathrm{C}$ under nitrogen atmosphere, according to the procedure described earlier [29]. $\mathrm{N}$-propylpiperazine dihydrobromide was neutralized with $2 \mathrm{M} \mathrm{NaOH}$ and extracted with dry chloroform. The chloroform layer was dried over anhydrous magnesium sulfate for $12 \mathrm{~h}$ to remove traces of water. The salt was removed by filtration and the filtrate was concentrated to obtain $\mathrm{N}$-propylpiperazine as yellow oil and used fresh to prevent oxidation.

$N$-propylpiperazine $(0.095 \mathrm{~mol}, 12.15 \mathrm{~g})$ and triethylamine $(0.095 \mathrm{~mol}, 9.59 \mathrm{~g})$ were dissolved in $300 \mathrm{ml}$ of dry THF in a three-neck Claisen flask. The reaction mixture was cooled in an ice bath, stirred using a magnetic stirring bar and maintained under a nitrogen atmosphere. Acryloyl chloride $(0.395 \mathrm{~mol}, 8.57 \mathrm{~g})$ dissolved in THF $(30 \mathrm{ml})$ was added dropwise into the reaction over a period of $30 \mathrm{~min}$ using a pressureequalizing funnel. The reaction mixture was stirred vigorously and was allowed to equilibrate to room temperature. The triethylamine hydrochloride salt was removed, and the filtrate was concentrated and distilled under vacuum. The product was obtained as pale-yellow oil at $86^{\circ} \mathrm{C}$ at a pressure of $7 \mathrm{mmHg}$.

\section{Synthesis of Copolymer Hydrogels}

Chemically crosslinked copolymer hydrogels of AcrNPP and PEGMA were synthesized by photopolymerization at $25{ }^{\circ} \mathrm{C}$ in bulk. The synthesis of hydrogel A9PE1 (containing 90\% AcrNPP and $10 \%$ PEGMA $)$ is described as follows: AcrNPP $(1.81 \mathrm{~g}, 0.0113 \mathrm{~mol})$, PEGMA $\left(0.20 \mathrm{~g}, 5.56 \times 10^{-4} \mathrm{~mol}\right)$, EGDMA $\left(0.04 \mathrm{~g}, 2.01 \times 10^{-4} \mathrm{~mol}\right)$, and DMPA ( $0.5 \mathrm{wt} \%$ based on the total weight of monomers and crosslinker) were dissolved in a glass ampoule (Wheaton). The mixture was degassed by bubbling dry nitrogen gas for $10 \mathrm{~min}$ to eliminate any dissolved oxygen. The sealed ampoule was sonicated for $2 \mathrm{~min}$ to remove any tiny air bubbles formed during the degassing process. Polymerization was carried out in a photochemical reactor 
(Rayonet) by UV irradiation $(\lambda \sim 285 \mathrm{~nm}$ ). The transparent solution turned into a solid gel within 20 min of irradiation. The solid gel was recovered by carefully cracking the ampoule, and the gel was washed in water for 3 days. It was then cut into thin rectangular slabs and dried to constant weight in a vacuum oven at $40{ }^{\circ} \mathrm{C}$. Hydrogels of various monomer compositions were similarly prepared. The monomer feed compositions and visual appearance of the other hydrogels prepared are given in Table I. The chemical structure of the hydrogel is shown in Fig. 1.

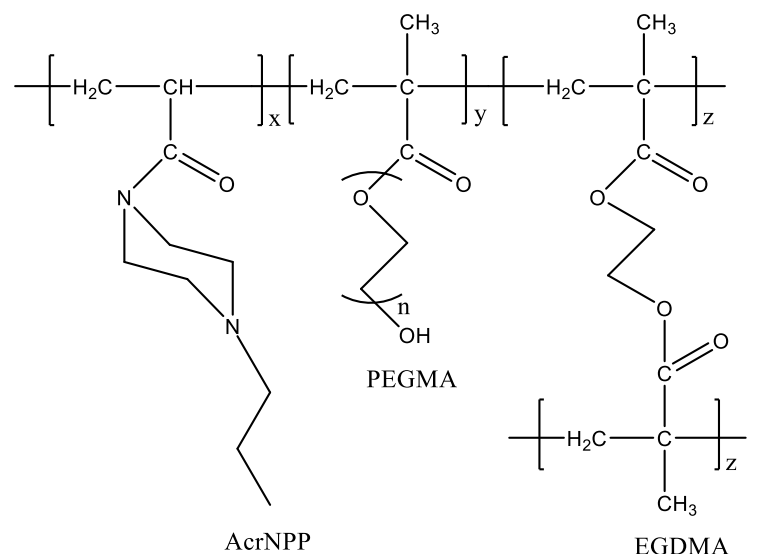

Fig. 1. Chemical structure of the hydrogel.

TABLE I: MONOMER FEED RATIOS, CONVERSION OF MONOMERS, AND APPEARANCE OF GELS

\begin{tabular}{cccccc}
\hline \multirow{2}{*}{ Hydrogel } & \multicolumn{2}{c}{ Monomer feed (mol\%) } & \multicolumn{2}{c}{ Appearance } & \multirow{2}{*}{ Conversion $(\%)$} \\
\cline { 2 - 5 } & AcrNPP & PEGMA & Before polymerization & After polymerization & 97 \\
A9PE1 & 90.31 & 9.69 & Clear solution & Solid transparent gel & 97 \\
A8PE2 & 80.10 & 19.90 & Clear solution & Solid transparent gel & 97 \\
A5PE5 & 50.15 & 49.85 & Clear solution & Solid transparent gel & 97 \\
\hline
\end{tabular}

All hydrogels contain 3 mol \% of EGDMA as chemical crosslinker.

\section{Equilibrium Swelling and Swelling Kinetics Studies}

Equilibrium swelling of the gels was studied gravimetrically to determine their response to $\mathrm{pH}$ changes. The gels were immersed and equilibrated in solutions of various $\mathrm{pH}$ at $23{ }^{\circ} \mathrm{C}$ for 1 day, and the swollen weight was recorded after carefully wiping the surface water with a damp lint-free Kim-wipe towel. The weight swelling ratio at equilibrium $W S R^{E q}$ was calculated using the following equation,

$$
W S R^{E q}=\frac{W_{s}-W_{d}}{W_{S}}
$$

where $W_{s}$ and $W_{t}$ are the equilibrium swollen weight and dry weight of the gel, respectively.

For the swelling kinetics study, the gels were cut into thin rectangular slabs (area $=1.5 \mathrm{~cm}^{2}$, thickness $0.4 \mathrm{~cm}$ ) and placed in solutions of $\mathrm{pH} 3$ and $\mathrm{pH} 9$ in glass vials at $23^{\circ} \mathrm{C}$. The weight of the swollen gels at different time intervals $\left(W_{t}\right)$ was measured gravimetrically. All measurements were repeated three times.

\section{E. Dye Sorption Measurements}

For the study of dye adsorption capacity of the hydrogels, Congo red (CR) was chosen as the model anionic dye. The hydrogels ( $\sim 0.05 \mathrm{~g})$ were immersed in aqueous CR dye solution of initial concentration $4 \times 10^{-5} \mathrm{M}$ for 7 days with gentle magnetic stirring. The amount of residual dye in the external solution was calculated by measuring the absorbance using a UV-Vis spectrophotometer (Perkin-Elmer Lambda 25) at a wavelength of $500 \mathrm{~nm}$. From the measured absorbance, the concentration of dye in the external solution was calculated using the Beer-Lambert law ${ }^{[39]}$. The adsorption capacity at equilibrium $q_{e q}\left(\mathrm{mg} \mathrm{g}^{-1}\right)$, and at time $t, q_{t}\left(\mathrm{mg} \mathrm{g}^{-1}\right)$ was calculated using the following respective equations:

$$
\begin{aligned}
& q_{e q}=\left(C_{i}-C_{e q}\right) \times \frac{V}{m} \\
& q_{t}=\left(C_{i}-C_{t}\right) \times \frac{V}{m}
\end{aligned}
$$

where $C_{i}$ is the initial concentration of dye $\left(\mathrm{mg} \mathrm{L}^{-1}\right), C_{e q}$ is the concentration of dye at equilibrium $\left(\mathrm{mg} \mathrm{L}^{-1}\right), C_{t}$ is the concentration of dye at time $t\left(\mathrm{mg} \mathrm{L}^{-1}\right), V$ is the volume of dye solution (L), and $m$ is the mass of hydrogel $(\mathrm{g})$. The percentage removal of dye by the hydrogel was calculated using the equation, 


\section{ADSORPTION KINETIC MODELS}

The dye adsorption mechanism of hydrogels and the rate controlling steps involved was established using various adsorption kinetic models [40]. The kinetic parameters obtained using these models are useful in predicting the rate of dye adsorption and modeling of the adsorption processes. In this study, the kinetics of CR adsorption onto the hydrogels was analyzed using pseudo-first order [41], pseudo-second order [42], Elovich [43], Avrami [44] and fractional power [45] kinetic models.

\section{A. Lagergren Pseudo-First Order Kinetic Model}

The pseudo first-order kinetic model described by Lagergren [41] is expressed as,

$$
\ln \left(q_{e}-q_{t}\right)=\ln q_{e}-k_{1} t
$$

where, $q_{e}$ is the amount of dye adsorbed at equilibrium $\left(\mathrm{mg} \mathrm{g}^{-1}\right), q_{t}$ is the amount of dye adsorbed at time $t$ $\left(\mathrm{mg} \mathrm{g}^{-1}\right)$, and $k_{1}$ is the rate constant for the pseudo-first-order adsorption $\left(\mathrm{min}^{-1}\right)$. A plot of $\ln \left(q_{e}-q_{t}\right)$ against $t$ at different concentrations gives a linear plot with a negative slope. The values of $k_{1}$ and $q_{c a l}$ are obtained from the slope and intercept, respectively.

\section{B. Ho Pseudo-Second-Order Kinetic Model}

The pseudo second-order kinetic model described by Ho [42] is given as,

$$
\frac{t}{q_{t}}=\frac{1}{k_{2} q_{e}^{2}}+\frac{1(t)}{q_{e}}
$$

where, $k_{2}$ is the pseudo-second order rate constant $\left(\mathrm{g} \mathrm{mg}^{-1} \mathrm{~min}^{-1}\right)$. A plot of $t / q_{t}$ against $t$ gives a linear plot with positive slope. The values of $k_{2}$ and $q_{e}$ are obtained from the slope and intercept, respectively.

\section{Elovich Kinetic Model}

The Elovich model [43] is used to describe second-order kinetics assuming that the actual solid surface of the adsorbent is energetically heterogeneous. The model describes a chemisorption process and is given by the following equation:

$$
q_{t}=\frac{1}{\beta} \ln (\alpha \beta)+\frac{1}{\beta} \ln t
$$

where, $\alpha$ is a constant related to rate of chemisorption and $\beta$ is a constant related to the extent of surface coverage of the adsorbent. A plot of $q_{t}$ versus $\ln t$ is linear, and the constants $\alpha$ and $\beta$ are obtained from the intercept and slope, respectively.

\section{Avrami Kinetic Model}

The linear form of Avrami kinetic model [44] is given by the following equation as,

$$
\ln \left[\ln \left(\frac{q_{e}}{q_{e}-q_{t}}\right)\right]=n_{\mathrm{Av}} \ln k_{\mathrm{Av}}+n_{\mathrm{Av}} \ln t
$$

where, $k_{\mathrm{Av}}$ is the Avrami adsorption kinetic constant, and $n_{\mathrm{Av}}$ is the Avrami model exponent time, which is related to the change in mechanism of adsorption. A plot of $\ln \left[\ln \left(\mathrm{q}_{\mathrm{e}} / \mathrm{q}_{\mathrm{e}}-\mathrm{q}_{\mathrm{t}}\right)\right]$ versus $\ln t$ is linear, and the constants $k_{\mathrm{Av}}$ and $n_{\mathrm{Av}}$ are obtained from the intercept and slope, respectively.

\section{E. Fractional Power Kinetic Model}

The linear form of the fractional power kinetic model ${ }^{[45]}$ is given by the following equation as,

$$
\log q_{t}=\log k+v \log t
$$

where, $k$ and $v$ are constants. The value of $n$ is usually less than 1 if the adsorption kinetic data fits the power functional model. A plot of $\log q_{t}$ versus $\log t$ is linear, and the constants $k$ and $v$ are obtained from the intercept (antilog) and slope, respectively. 


\section{ADSORPTION MECHANISM}

The mechanism of dye adsorption by the hydrogels was investigated using the intra-particle diffusion model (Weber and Morris model) [46], and pore-diffusion model (Bangham model) [47].

\section{A. Intraparticle Diffusion Model}

The intraparticle diffusion model by Weber and Morris [46] is given by the equation as,

$$
q_{t}=k_{\mathrm{diff}} t^{1 / 2}+C
$$

where $q_{t}\left(\mathrm{mg} \mathrm{g}^{-1}\right)$ is the amount of dye adsorbed by the hydrogels at time $t$, and $k_{\text {diff }}\left(\mathrm{mg} \mathrm{g}^{-1} \min ^{-1 / 2}\right)$ is the rate constant for intraparticle diffusion. The value of the slope $C$ provides information on the thickness of the boundary layer, and the value of the intercept gives information on boundary layer effect. A large intercept suggests a large boundary layer effect.

A plot of $q_{t}$ versus $t^{1 / 2}$ is either linear or multilinear. A linear trend indicates that intraparticle diffusion is involved in the adsorption process, and a multilinear trend indicates that the adsorption is governed by two or more steps. A linear plot with the plot passing through the origin indicates that the entire rate-limiting step of the adsorption process is solely by intraparticle diffusion [48].

\section{B. Pore-Diffusion Model}

The Bangham model [47] evaluates if the adsorption process is pore-diffusion controlled, and is given by the equation as,

$$
\log \log \left(\frac{C_{i}}{C_{i}-q_{t} m}\right)=\log \left(\frac{K_{j} m}{2.303 V}\right)+\alpha \log t
$$

where, $C_{i}$ is the initial concentration of the dye solution $\left(\mathrm{mg} \mathrm{L}^{-1}\right), V$ is the volume of dye solution $(\mathrm{mL}), m$ is the mass of adsorbent $(\mathrm{g})$. A plot of $\log \log \left(C_{i} / C_{i}-q_{t} m\right)$ versus $\log t$ is linear, and the constants $\alpha$ and $K j$ are obtained from the slope and intercept, respectively.

\section{RESULTS AND DISCUSSIONS}

\section{A. General Characteristics of Hydrogels}

The hydrogels were prepared by photo-polymerization in bulk at $25{ }^{\circ} \mathrm{C}$, and transparent solid gels were obtained within 20 min of reaction. The conversion ratio of monomer $\left(C^{M o n}\right)$ was estimated based on the following equation,

$$
C^{M o n}(\%)=\frac{W_{d}}{W_{m}} \times 100
$$

where, $W_{m}$ and $W_{d}$ are the total weight of monomers before polymerization and dry weight of gel after polymerization, respectively. The conversion ratio of monomers was almost $97 \%$ for all the monomer feeds. This high conversion of monomers indicates an efficient crosslinking reaction between the monomers and the difunctional crosslinker. As the conversion ratio was $97 \%$, the mole ratio of monomer units in the resulting gels was assumed to be equal to the initial monomer feed composition [24].

\section{B. Effect of PEGMA on the Swelling of Gels in Water}

The effect of hydrophilic comonomer PEGMA, on the swelling behavior of the gels was studied in water $(\mathrm{pH} 6.5)$ at $23^{\circ} \mathrm{C}$. The time-dependent swelling behavior of the gels is shown in Fig. 2.

Two significant swelling profiles (an initial rapid increase followed by a decrease) are observed for all the three gels as function of time. The initial rapid increase (overshooting effect) in swelling ratio is attributed to the hydrophilic nature of PEGMA in the gel which facilitates rapid diffusion of water molecules into the gel matrix. Upon reaching the maximum swelling ratio, the elasticity of the gel network diminishes leading to the physical breaking (formation of small cracks) of the gel. This leads to the observed decrease in swelling ratio of the gels above the maximum swelling ratio. In general, polymers prepared by bulk polymerization are glassy with low elasticity, and as a result do not swell to high swelling ratios [31]. Hydrolysis of the ester functional group of PEG blocks by the adsorbed water molecules is another factor that leads to disintegration of the gel, leading to a decrease in swelling ratio [49]. 


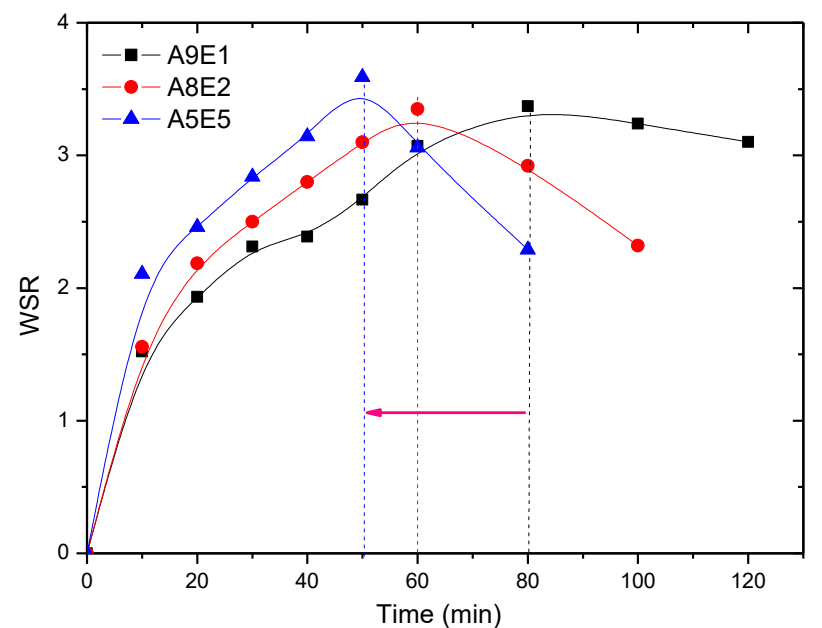

Fig. 2. Effect of PEGMA content on the swelling of hydrogels in water at $23{ }^{\circ} \mathrm{C}$.

The gel A5PE5 containing the highest amount of PEGMA shows the maximum swelling ratio of 3.5 followed by the gels A8PE2 and A9PE1. Also, the gel A5PE5 reaches the maximum swelling ratio at 50 min followed by A8PE2 at $60 \mathrm{~min}$, and A9PE1 at $80 \mathrm{~min}$. The time taken to reach the maximum swelling ratio in water is thus dependent on PEGMA content in the gels. This water-responsive property is attributed to the hydrophilic nature of the ethylene oxide blocks of PEGMA, which facilitate the formation of hydrogen bonding with surrounding water molecules [50]. Hydrogels containing PEGMA is widely used in drug delivery systems owing to this PEGMA dependent swelling and biocompatibility [51]. The maximum swelling ratio of the gels decrease in the following order A5PE5 > A8PE2 > A9PE1. The gel A5PE5 containing the highest amount of PEGMA ( $49.85 \mathrm{~mol} \%$ ) disintegrates faster followed by A8PE2 $(19.90 \mathrm{~mol} \%)$ and A9PE1 (9.69 mol \%) containing lower amounts of PEGMA. This disintegration is attributed to the hydrolysis of ester linkage of PEGMA units in the hydrogel [49], [52]. As the gel A9PE1 exhibited maximum swelling at longer time without any disintegration, this gel was chosen for further study.

\section{Effect of $p H$ on the swelling of gel}

The time-dependent swelling of the gel A9PE1 containing $90.31 \mathrm{~mol} \%$ of AcrNPP in solution of $\mathrm{pH} 3.1$ and $\mathrm{pH} 9.1$ was studied, and the results are shown in Fig. 3. The gel swells more in acidic solution than in basic solution with initial rapid swelling during the first $10 \mathrm{~min}$. The tertiary amine containing monomer unit AcrNPP is primarily responsible for higher swelling at $\mathrm{pH}$ 3.1. Under the acidic condition, the tertiary amine nitrogen is protonated leading to the formation of fixed charges on the gel network. This in turn causes electrostatic repulsion between the charged polymer network leading to the expansion of gel network thereby facilitating diffusion of water into the matrix. The $p K_{\mathrm{a}}$ of AcrNPP is 4.1 [24], [29] and below this (at $\mathrm{pH} 3.1$ ) the tertiary amine nitrogen is fully protonated. As a result, the gel exhibits a high weight-swelling ratio of 7 in acidic solution with an equilibrium water content of about 97\%. At $\mathrm{pH} 9.1,(\mathrm{pH}>\mathrm{pKa})$ the protonation of tertiary amine nitrogen is insignificant and swelling ratio of the gel is only 4 , which is solely due to water diffusion into the glassy matrix of the gel [52], [53]. This important property of ionization by tuning the external $\mathrm{pH}$ allows to develop $\mathrm{pH}$-responsive gels with tunable swelling properties.

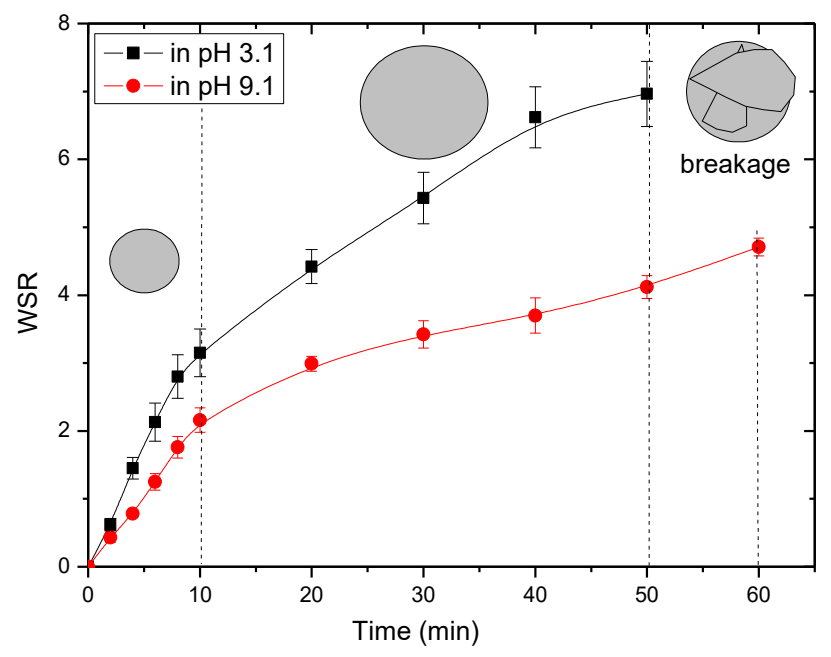

Fig. 3. Effect of external $\mathrm{pH}$ on the swelling of hydrogels at $23^{\circ} \mathrm{C}$. 


\section{Effect of Temperature on the Swelling of Gel}

The temperature-responsive swelling of the gel A9PE1 in water $(\mathrm{pH} 6.5)$ was studied and the results are shown in Fig. 4.

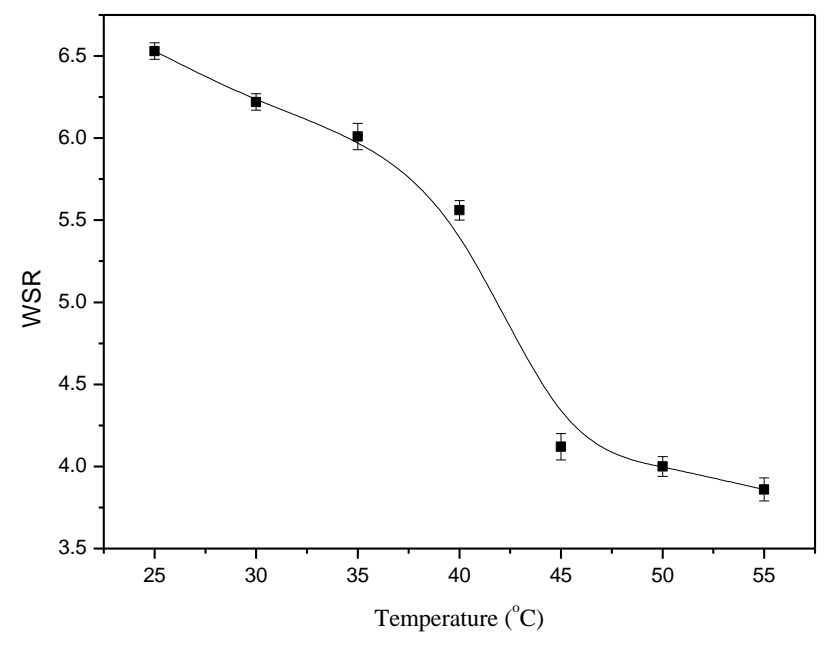

Fig. 4. Effect of temperature on the swelling of hydrogel A9PE1 in water.

The swelling ratio decreases steadily with increase in temperature and is more significant above $35^{\circ} \mathrm{C}$. This decrease in swelling ratio with increase in temperature is a fundamental property of thermo-shrinking gels or negative-temperature responsive gels [54]. The linear polymer, poly $(N$-acryloyl- $N$ '-propyl piperazine) (PAcrNPP) exhibits a lower critical solution temperature (LCST) at $38{ }^{\circ} \mathrm{C}$ in water [29]. For the linear copolymer of AcrNPP with PEGMA of composition 90:10, the LCST was determined to be $44.75 \pm 0.5^{\circ} \mathrm{C}$. The LCST of this random copolymer is higher than that of PAcrNPP, due to the presence of hydrophilic PEGMA units along the polymer backbone. The hydrogel of this polymer is thus expected to shrink around this temperature in water due to hydrophobic interactions.

\section{E. Effect of Initial Dye Concentration}

The effect of initial concentration of the dye on the uptake by the hydrogel A9PE1is shown in Fig. 5. As expected, the dye uptake capacity of the hydrogel increases with increase in concentration of the dye solution. This indicates that the initial concentration of dye plays an important role in the quantity of dye adsorbed by the hydrogel. The initial rapid increase in the quantity of dye adsorbed is attributed to the swelling of gel and contact of the dye molecules with the available surface adsorption sites. Interestingly, the swelling ratio of the hydrogel deceased with increase in dye concentration. This is due to the formation of additional physical crosslinks between the dye molecule and the polymer chains, which prevents further swelling of the hydrogel [55].

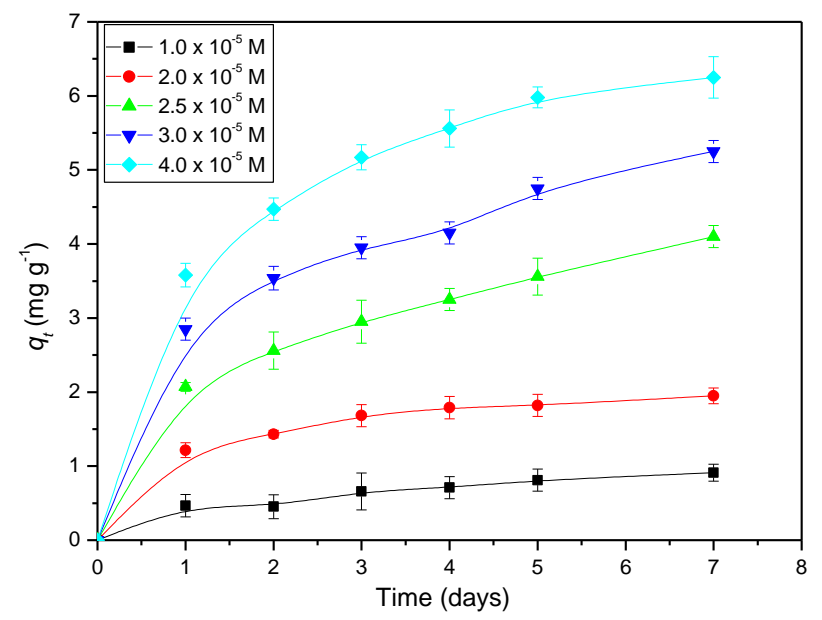

Fig. 5. Effect of dye concentration on the dye uptake capacity of hydrogel A9PE1 at $23{ }^{\circ} \mathrm{C}$.

\section{F. Effect of Temperature on Dye Adsorption}

The effect of temperature on the adsorption capacity of the hydrogel A9PE1 at $25{ }^{\circ} \mathrm{C}, 35^{\circ} \mathrm{C}$, and $45{ }^{\circ} \mathrm{C}$ was studied, and the results are shown in Fig. 6. It is evident that the amount of dye adsorbed by the hydrogel 
decreases with increase in temperature. The decrease is significant above $35^{\circ} \mathrm{C}$ due to the dominance of hydrophobic interactions above this temperature. The hydrophobic interactions cause the formation of a 'skin' like texture on the surface [24], [30] of the hydrogel which prevents the diffusion of dye and water molecules into the gel matrix thereby decreasing the dye adsorption capacity of the hydrogel.

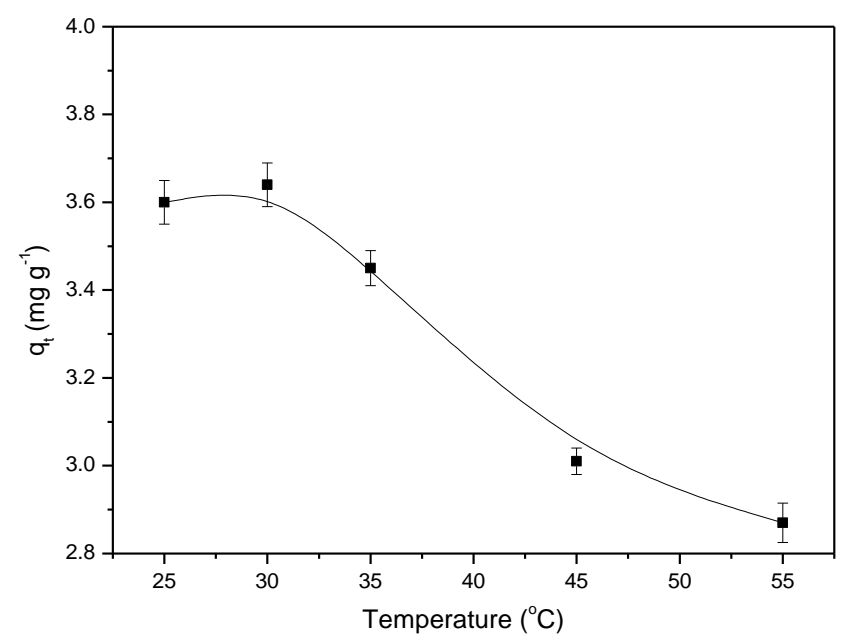

Fig. 6. Effect of temperature on the dye uptake capacity of hydrogel A9PE1.

\section{G. Adsorption Kinetics Studies}

The study of dye adsorption kinetics of any new material is important as it gives vital information about the nature and mechanism of the adsorption process. In this study, seven kinetic models [41]-[47] were employed to best understand the dye adsorption process and mechanism of adsorption by the new hydrogels. The adsorption kinetic parameters obtained from the respective plots are summarized in Table II.

TABLE II: AdSORPTION KINETICS PARAMETERS OBTAINED FROM VARIOUS KINETIC MODELS FOR ADSORPTION OF CR ONTO THE HYDROGEL. INITIAL CONCENTRATION OF CR $=4 \times 10^{-5} \mathrm{M}$

\begin{tabular}{llcl}
\hline \multicolumn{1}{c}{ Kinetic model } & \multicolumn{1}{c}{ Kinetic parameters Regression } \\
\hline Pseudo first order & $\mathrm{q}_{\mathrm{e}}$ cal. $(\mathrm{mg} / \mathrm{g})=4.58$ & $\mathrm{k}_{1}\left(\mathrm{~min}^{-1}\right)=1.86 \times 10^{-4}$ & $\mathrm{R}^{2}=0.9952$ \\
Pseudo second order & $\mathrm{q}_{\mathrm{e}}$ cal. $(\mathrm{mg} / \mathrm{g})=4.36$ & $\mathrm{k}_{2}(\mathrm{~g} / \mathrm{mg} \mathrm{min})=0.134$ & $\mathrm{R}^{2}=0.9991$ \\
Elovich & $\alpha(\mathrm{mg} / \mathrm{g} \mathrm{min})=1.05 \times 10^{-3}$ & $\beta(\mathrm{g} / \mathrm{mg})=1.43$ & $\mathrm{R}^{2}=0.9967$ \\
Avrami & $\mathrm{n}_{\mathrm{Av}}=2.182$ & $\mathrm{k}_{\mathrm{Av}}\left(\mathrm{min}^{-1}\right)=3.03 \times 10^{-3}$ & $\mathrm{R}^{2}=0.9903$ \\
Fractional power & $V\left(\mathrm{~min}^{-1}\right)=0.298$ & $\mathrm{k}(\mathrm{mg} / \mathrm{g})=0.418$ & $\mathrm{R}^{2}=0.9936$ \\
Intra-particle diffusion* & $\mathrm{C}(\mathrm{mg} / \mathrm{g})=2.10$ & $\mathrm{k}_{\mathrm{diff}}\left(\mathrm{mg} / \mathrm{g} \mathrm{min} \min ^{1 / 2}\right)=0.044$ & $\mathrm{R}^{2}=0.9830$ \\
Pore-diffusion & $\alpha=1.17 \times 10^{-4}$ & $\mathrm{k}_{\mathrm{j}}(\mathrm{g})=1.98$ & $\mathrm{R}^{2}=0.9940$ \\
\hline
\end{tabular}

* data obtained from linear regression fit.

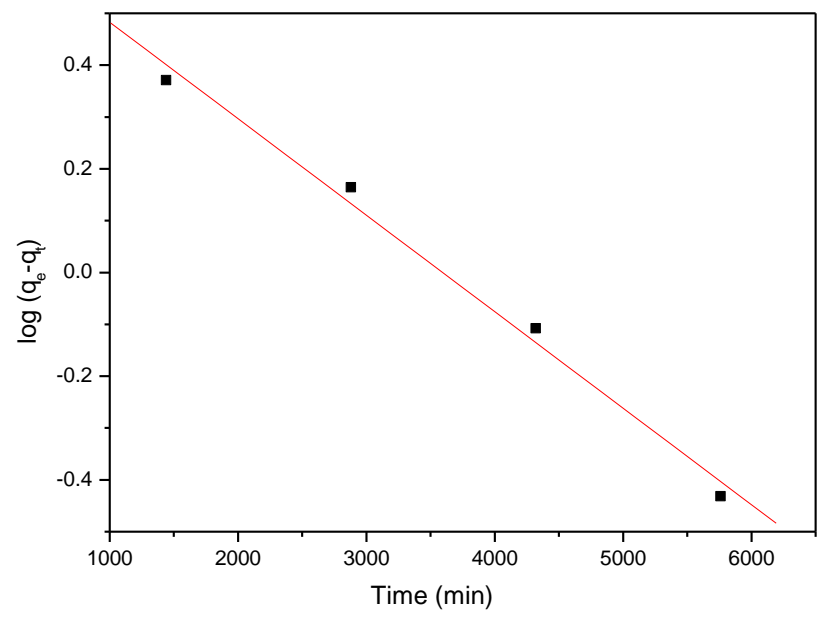

Fig. 7. Dye adsorption kinetics fitted with Lagergren pseudo-first order kinetic model. The solid red line corresponds to the modelfit on the experimental data.

The plot based on pseudo first-order model is shown in Fig. 7. As expected, the plot is linear with a negative slope. However, the linear regression coefficient $\left(\mathrm{R}^{2}\right)$ is 0.9952 which indicates that the adsorption of CR by the hydrogel does not follow a first-order kinetic process. The plot based on pseudo second-order 
model is shown in Fig. 8. The plot is linear with a positive slope with a regression coefficient of 0.9991. The initial adsorption rate $(h)$ defined as, $h=k_{2} \times q_{e}^{2}$ was $0.667 \mathrm{~min}^{-1}$ for the initial CR concentration of $4 \times 10^{-4} \mathrm{M}$. The qe value obtained from this model was $4.98 \mathrm{mg} / \mathrm{g}$ which is in good agreement with the experimentally observed value of $5.63 \mathrm{mg} / \mathrm{g}$. These results suggest that the adsorption of CR onto the hydrogel follow a pseudo-second order kinetic process.

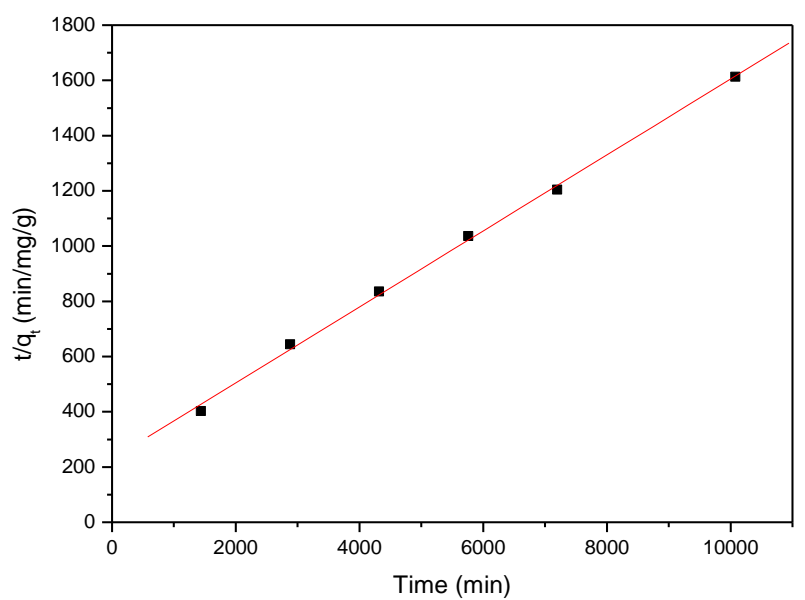

Fig. 8. Dye adsorption kinetics fitted with Ho second order kinetic model. The solid red line corresponds to the model-fit on the experimental data.

In addition, many hydrogels swell in water following a second-order swelling kinetics [24], [30], [31]. In the adsorption of CR by the hydrogel, the rate-limiting step appears to be a chemical interaction involving exchange and sharing of electrons between the tertiary amino moiety of AcrNPP and the dye molecule [32], [55]. Similar adsorption process has been observed for cationic hydrogels based on dimethylaminoethyl methacrylate [56], [57].

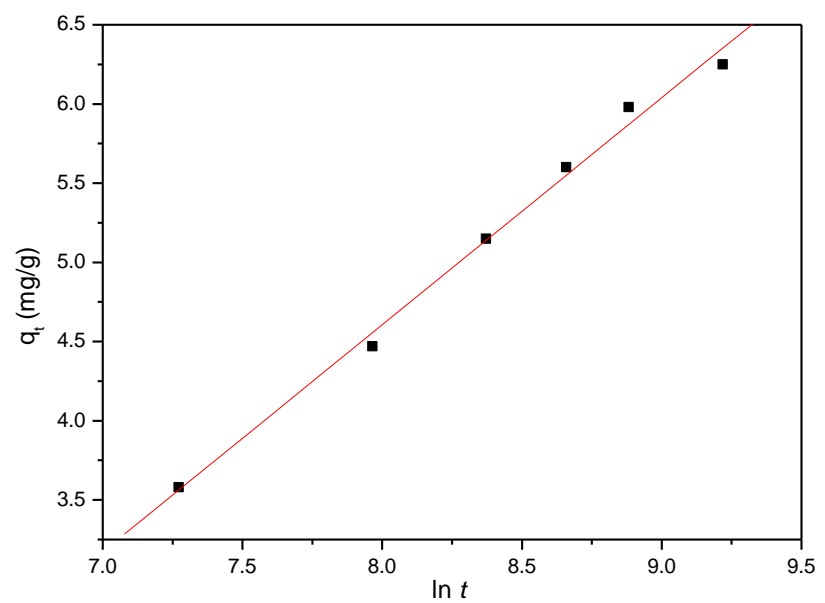

Fig. 9. Dye adsorption kinetics fitted with Elovich kinetic model. The solid red line corresponds to the model-fit on the experimental data.

Fig. 9 shows the plot based on Elovich kinetic model. The plot is linear with a regression coefficient of 0.9967. The constant $\beta$, obtained from the slope of the plot, which is related to the extent of surface coverage was $1.433 \mathrm{~g} / \mathrm{mg}$ for the initial dye concentration of $4 \times 10^{-4} \mathrm{M}$. In general, this value increases with increase in initial dye concentration. The constant $\alpha$, that is related to the rate of chemisorption was $-6.862 \mathrm{mg} / \mathrm{g}$ min. This low value indicates that the adsorption of CR by the hydrogel follow more than one adsorption mechanism [2], [3]. 


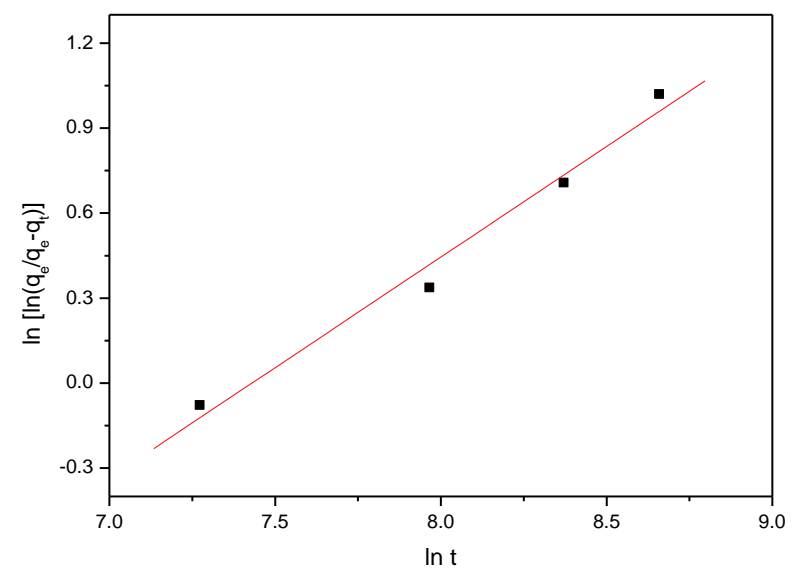

Fig. 10. Dye adsorption kinetics fitted with Avrami kinetic model. The solid red line corresponds to the model-fit on the experimental data.

The plot based on Avrami kinetic model is shown in Fig. 10. The plot is linear with a positive slope and low regression coefficient of 0.9903 . The low regression coefficient suggests that the adsorption of CR by the hydrogel does not follow the Avrami model.

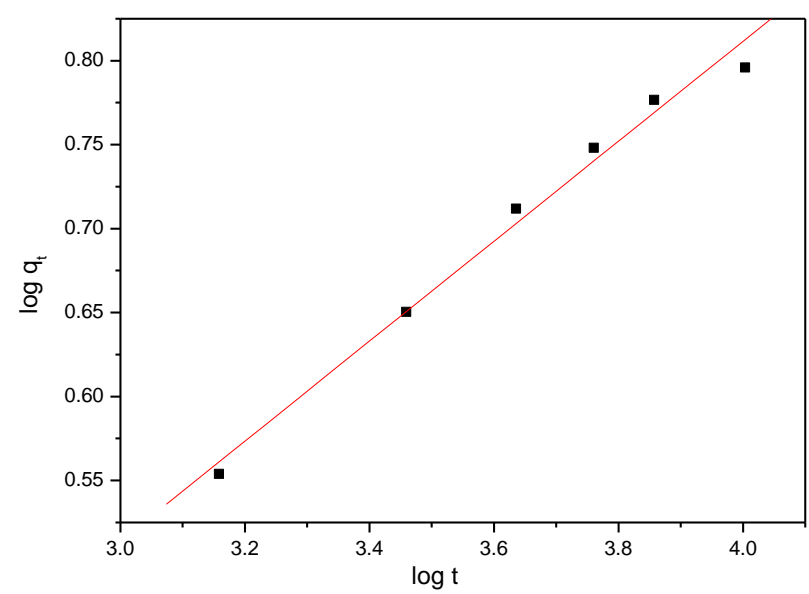

Fig. 11. Dye adsorption kinetics fitted with fractional power kinetic model. The solid red line corresponds to the model-fit on the experimental data.

The plot of fractional power kinetic model is shown in Fig. 11. The plot is linear with a regression coefficient of 0.9936 . The constant $v$ obtained from the plot is 0.2977 which is less than unity, and this indicates that kinetic data fits well with power function model.

\section{H. Adsorption Mechanism}

The plots based on intraparticle diffusion model (Weber-Morris model) and pore-diffusion model (Bangham model) are shown in Fig. 12 and 13, respectively.

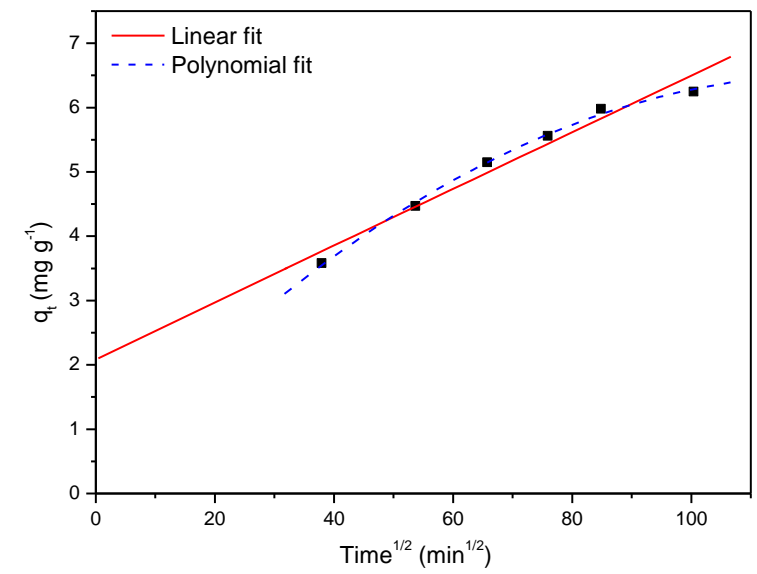

Fig. 12. Dye adsorption fitted with intraparticle diffusion model. The solid red line corresponds to the model-fit on the experimental data. 


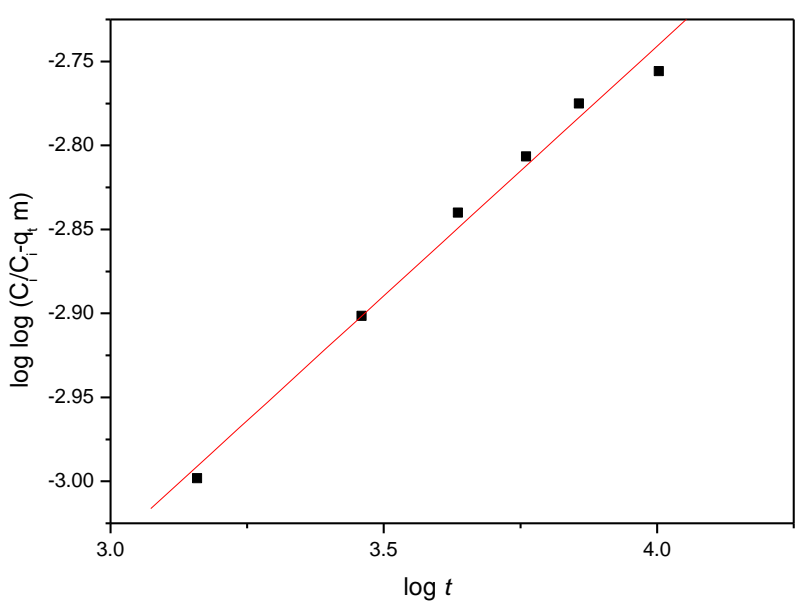

Fig. 13. Dye adsorption fitted with pore-diffusion diffusion model. The solid red line corresponds to the model-fit on the experimental data.

The plot of intraparticle diffusion model is not linear $\left(\mathrm{R}^{2}=0.9830\right)$ but multi-linear. The linear fit does not pass through zero, which clearly indicates that the adsorption does not follow single diffusion mechanism and the sole rate-determining step is not intraparticle diffusion [2]. The multi-linearity thus indicates that multi-steps are involved in the adsorption of CR by the hydrogel. The initial linear portions of the curve do not pass through the origin of the curve, indicating that intraparticle diffusion is not the only rate limiting step. The slope of this line is sharper $\left(\mathrm{k}_{\text {initial }}=0.059 \mathrm{mg} \mathrm{g}^{-1} \mathrm{~h}^{-1 / 2}\right)$ which suggests that boundary layer diffusion of dye molecules (fast surface uptake) takes place during the initial stage of adsorption. The second linear region of the plot $\left(\mathrm{k}_{\text {later }}=2.070 \mathrm{mg} \mathrm{g}^{-1} \mathrm{~h}^{-1 / 2}\right)$ is less steep and this is attributed to the diffusion of the surface adsorbed dye molecules within the porous matrix of the hydrogel, where intraparticle diffusion becomes the rate limiting step. Similar adsorption mechanism has been reported for cationic hydrogels based on DMAEMA and Karaya gum [58], and for Rhodamine B dye adsorption onto Raphia hookerie fruit epicarp [2].

The plot based on Bangham model (Fig. 13) is linear with a regression coefficient of 0.9940, suggesting that pore diffusion is also involved in the uptake of CR by the hydrogel. Deviation from linearity is observed at longer time which further suggests that adsorbate pore diffusion is not the only rate limiting step in this adsorption [2], [32], [56]-[58].

\section{CONCLUSIONS}

New multiple stimuli responsive copolymer hydrogels based on PAcrNPP and PEGMA were synthesized by UV-light initiated bulk polymerization. The amount of PEGMA in the hydrogels played a significant role affecting many properties such as swelling, dye adsorption, and erodibility. This material shows promising applications in the removal of anionic dyes from water and the stimuli-responsive property can be used as an on-off switch. The adsorption of dye was a multistep process with surface adsorption followed by intraparticle diffusion.

\section{ACKNOWLEDGMENT}

GRD thanks the Nanyang Technological University, National Institute of Education for the financial support under the academic research grant NIEAcRF. MCH thanks Nanyang Technological University for the post-graduate research scholarship.

\section{CONFLICT OF INTEREST}

Authors declare that they do not have any conflict of interest.

\section{REFERENCES}

[1] de Menezes EW, Lima EC, Royer B, de Souza FE, dos Santos DB, Gregório JR, et al. Ionic silica based hybrid material containing the pyridinium group used as an adsorbent for textile dye. J. Colloid Interface Sci., 2012;378(1):10-20.

[2] Inyinbor AA, Adekola FA, Olatunji GA. Kinetics, isotherms and thermodynamic modeling of liquid phase adsorption of Rhodamine B dye onto Raphia hookerie fruit epicarp. Water Res. Ind. 2016; 15:14-27. 
[3] Gupta V, Suhas AA, Saini V. Removal of Rhodamine B, Fast Green, and Methylene Blue from wastewater using red mud, an aluminum industry waste. Ind. Eng. Chem. Res. 2004; 43(7):1740-1747.

[4] Yemendzhiev H, Alexieva Z, Krastanov A. Decolorization of synthetic dye Reactive Blue 4 by Mycelial culture of White-Rot fungi Trametes Versicolor 1. Biotechnol. Biotechnol. Equip. 2009; 23(3):1337-1339.

[5] Duruibe JO, Ogwuegbu MOC, Egwurugwu JN. Heavy metal pollution and human biotoxic effects. Int. J. Phys. Sci. 2007; 2:112118.

[6] Kadirvelu K, Kavipriya M, Karthicka C, Radhika M, Vennilamani N, Pattabhi S. Utilization of various agricultural wastes for activated carbon preparation and application for the removal of dyes and metal ions from aqueous solutions Biores. Technol. 2003; 87(1):129-132.

[7] Weisburger E. Cancer-causing chemicals. In Cancer-The outlaw cell, R.F. LaFond Ed.; American Chemical Society, Washington DC. 1978, pp. 173-186.

[8] Roshan Deen G. Environmental application: Hydrogels. In Encyclopedia of polymer applications, Vol 1, M. Misra Ed. Taylor and Francis. 2019.

[9] Simate GS, Iyuke SE, Ndlovu S, Heydenrych M. The heterogeneous coagulation and flocculation of brewery wastewater using carbon nanotubes. Water Res. 2012; 46(4):1185-1197.

[10] Cayllahua J, Torem M. Biosorptive flotation of nickel and aluminium ions from aqueous solution. Desalination. 2011; 279(S13):195-200.

[11] Khayet M, Zahrim A, Hilal N. Modelling and optimization of coagulation of highly concentrated industrial grade leather dye by response surface methodology. Chem. Eng. J. $2011 ; 167(1): 77-83$.

[12] Irawan C, Kuo Y-L, Liu J. Treatment of boron-containing optoelectronic wastewater by precipitation process. Desalination. 2011; 280:146-151.

[13] Kwak NS, Park H-M, Hwang TS. Preparation of ion-exchangeable nanobeads using suspension polymerization and their sorption properties for indium in aqueous solution. Chem. Eng. J. 2012; 191: 579-587.

[14] Alventosa-deLara E, Barredo-Damas S, Alcaina-Miranda M, Iborra-Clar M.Ultrafiltration technology with a ceramic membrane for reactive dye removal : optimization of membrane performance. J. Hazard. Mater. 2012 ; 209-210: 492-500.

[15] Lu N, Zhao Y, Liu H, Guo Y. Yuan X, Xu H, et al. Design of polyoxometallate-titania composite film $\left(\mathrm{H}_{3} \mathrm{PW}_{12} \mathrm{O}_{40} / \mathrm{TiO}_{2}\right)$ for thee degradation of an aqueous dye Rhodamine B under the simulated sunlight irradiation. J. Hazard Mater. 2012; 199-200: 18.

[16] Gomes AC, Fernandes LR, Simöes RMS. Oxidation rates of two textile dyes by ozone: Effect of pH and competitive kinetics. Chem. Eng. J. 2012; 189-190:175-181.

[17] Mahmoodi NM, Hayati B, Arami M, Mazaheri F. Single and binary system dye removal from colored textile wastewater by a dendrimer as a polymeric nanoarchitecture: equilibrium and kinetics. J. Chem. Eng. Data. 2010; 55(11):4660-4668.

[18] Oller I, Malato S, Sánchez-Perez J. Combination of advanced oxidation processes and biological treatments for wastewater decontamination-a review. Sci. Total Environ. $2011 ; 409(20)$ : 4141-4166.

[19] Amin NK. Removal of direct blue-106 dye from aqueous solution using new activated carbons developed from pomegranate peel : adsorption equilibrium and kinetics. J. Hazard Mater. 2009; 165(1): 52-62.

[20] Nesic AR, Velickovic SJ, Antonovic DG. Characterization of chitosan/montmorillonite membranes as adsorbents for Bezactiv Orange V-3R dye. J. Hazard. Mater. 2011; 209-210: 256-263.

[21] Dawood S, Kanti Sen T. Removal of anionic dye Congo red from aqueous solution by raw pine and acid-treated pine cone powder as adsorbent: equilibrium, thermodynamic, kinetics, mechanism and process design. Water Res. 2012; 46(6):1933-1946.

[22] Deng S, Ting YP. Polyethylenimine-modified fungal biomass as a high-capacity biosorbent for $\mathrm{Cr}(\mathrm{VI})$ anions: sorption capacity and uptake mechanism. Environ. Sci. Technol. $2005 ; 39(21): 8490-8496$.

[23] Liu Y, Zheng Y, Wang A. Enhanced adsorption of Methylene Blue from aqueous solution by chitosan-g-poly(acrylic acid)/vermiculite hydrogel composites. J. Environ. Sci. 2010 ; 22(4): 486-493.

[24] Roshan Deen G, Teo TW, Lee KF. New stimuli-responsive polyampholyte: effect of chemical structure and composition on solution properties and swelling mechanism. Polymer $2016 ; 104: 91-103$.

[25] Roshan Deen G, Lim ZL, Mah CH, Tng SQ, Sakthivel M, Lim YQ, el al. Network structure and Congo red dye removal characteristics of new temperature-responsive hydrogels. Sep. Sci. Technol. 2015; 50(1):64-71.

[26] An F, Feng X, Gao B. Adsorption property and mechanism of composite adsorbent PMMA/SiO 2 . J. Hazard. Mater. 2010; 178(13):499-504.

[27] Panic VV, Madzarevic ZP, Volkov-Husovic T, Velickovic SJ. Poly(methacrylic acid) based hydrogels as sorbents for removal of cationic dye basic yellow 28: kinetics, equilibrium study and image analysis. Chem. Eng. J. 2013; 217: 192-204.

[28] Milosavljevic NB, Ristic M, Peric-Grujic A, Filipovic JM, Strbac SB, Rakocevic ZL, et al. Sorption of zinc by novel pH-sensitive hydrogels based on chitosan, itaconic acid and methacrylic acid. J. Hazard Mater. 2011: 192(2): 846-854.

[29] Roshan Deen G, Mah CH, Influence of external stimuli on the network properties of cationic poly $(N$-acryloyl- $N$ '-propyl piperazine) hydrogels. Polymer 2016; 89:55-68.

[30] Roshan Deen G, Gan LH. Determination of reactivity ratios and swelling characteristics of stimuli-reposive copolymers of $N$ acryloyl- $N$ '-ethyl piperazine and MMA. Polymer 2006: 47 5025-5034.

[31] Peppas NA, Bures P, Leobandung W, Ichikawa H. Hydrogels in pharmaceutical formulations. Eur. J. Pharm. Biopharma. 2000; 50:27-46.

[32] Karthika JS, Vishalakshi B. Novel stimuli responsive gellan gum-graft-poly(DMAEMA) hydrogel as adsorbent for anionic dye. Int. J. Biolog. Macromol. 2015; $50: 648-655$.

[33] Malana MA, Ijaz S, Ashiq MN. Removal of various dyes from aqueous media onto polymeric gels by adsorption process : their kinetics and thermodynamics. Desalination 2010; 263: 249-257.

[34] Wang H, Ji X, Ahmed M, Huang F, Sessler JL. Hydrogels for anion removal from water. J. Mater. Chem. A. 2019; 7: 13941403 .

[35 Samaddar P, Kumar S, Kim KH. Polymer hydrogels and their applications toward sorptive removal of potential aqueous pollutants. Polym. Rev. 2019; 59: 418-464.

[36] Tran VV, Park D, Lee YC. Hydrogel applications for adsorption of contaminants in water and wastewater treatment. Envir. Sci. Poll. Res. 2018; 25: 24569-24599.

[37] Khan M, Lo I. A holistic review of hydrogel applications in the adsorptive removal of aqueous pollutants: recent progress, challenges and perspectives. Water Res. 2016; 106: 259-271.

[38] Varghese S, Lele AK, Srinivas D, Mashelkar RA. Role of hydrophobicity on structure of polymer-metal complexes. J. Phys. Chem. B. 2001; 105: 5368-5373.

[39] Swinehart DF. The Beer-Lambert Law. J. Chem. Edn. 1962; 39(7): 333-337.

[40] Anastopoulos I, Kyaz GZ. Agricultural peels for dye adsorption: a review of recent literature. J. Mol. Liq. 2014; 200: 381-389.

[41] Lagergren S, Svenska BK. On the theory of so-called adsorption of materials. R. Swed. Acad. Sci. Doc Band 1898; 24: 1-13.

[42] Ho YS, McKay G. Pseudo-second order model for sorption processes. Proc. Biochem. 1999; 34(5): 451-465. 
[43] Aharoni C, Ungarish M. Kinetics of activated chemisorption. Part 1. The non-elovichian oart of the isotherm. J. Chem. Soc. Faraday Trans. 1976; 72: 265-268.

[44] Avrami M. Kinetics of phase change. II Transformation-time relations for random distribution of nuclei. J. Chem. Phys. 1940; 8: $212-224$

[45] Dalal RC. Desorption of soil phosphate by anion-exchange resin. Commun. Soil Sci. Plant Anal. 1974; 5(6): 531-535.

[46] Weber WJ, Morris JC. Kinetics of adsorption on carbon from solutions. J. Sanity Eng. Div. Am. Soc. Civil Eng. 1963; 89: 3159.

[47] Bhatnagar A, Jain AK. A comparative adsorption study with different industrial wastes as adsorbents for the removal of cationic dyes from water. J. Colloid Interface Sci. 2005; 281(1): 49-55.

[48] Arami M, Limaee NY, Mahmoodia NM. Evaluation of the adsorption kinetics and equilibrium for the potential removal of acid dyes using a biosorbent. Chem. Eng. J. 2000; 139(1): 2-10.

[49] Zustiak SP, Leach JB. Hydrolytically degradable poly(ethylene glycol) hydrogel scaffolds with tunable degradation and mechanical properties. Biomacromolecules 2010; 11(5): 1348-1357.

[50] Venault A, Wu JR, Chang Y, Aimar P. Fabricating hemocompatible bi-contniuous PEGylated PVDF membranes via vaporinduced phase inversion. J. Membr. Sci. 2014; 470: 18-21.

[51] Tayo LL, Venault A, Constantino VCR, Caparanga AR, Chinnathambi A, Alhorbi SA, et al. Design of hemocompatible poly(DMAEMA-co-PEGMA) hydrogels for controlled release of insulin. J. Appl. Polym. Chem. $2015 ; 132(32)$ : 42365-42377.

[52] Zhao Y, Yang Y, Yang X, Xu H. Preparation and $\mathrm{pH}$-sensitive swelling behaviour of physically crosslinked polyampholyte gels. J. Appl. Polym. Sci. $2006 ; 102(4)$ : 3857-3861.

[53] Kakinoki S, Kaetsu I, Nakayama M, Sutani K,Uchida K, Yukutake K. Temperature and pH responsiveness of poly(DMAA-counsaturated carboxylic acid) hydrogels synthesized by UV-irradiation. Radiat. Phys. Chem. 2003; 63: 685-693.

[54] Wilson AN, Blenner M, Giuseppe-Elie A. Polyplex formation influences release mechanism of mono-and di-valent ions from phosphorylcholine group bearing hydrogels. Polymer 2014; 6(9): 2451-2472.

[55] Mah CH, Structure-property-application relationship of new stimuli-responsive polymers based on N-acryloyl-N'propylpiperazine. Ph.D. Thesis, Nanyang Technological University; 2018.

[56] Liang S, Tang J, Yao S, Zhu W. Removal characteristics of two anionic dyes by a polyethylenimine/poly(N,Ndimethylaminoethyl methacrylate) gel. RSC Adv. 2019; 9: 22907-22920.

[57] Cheng Q, Li C, Xu L, Li J, Zhai M. Adsorption of Cr(VI) ions using the amphiphilic gels based on 2-(dimethylamino)ethyl methacrylate modified with 1-bromoalkanes. Chem. Eng. J. 2011; 173(1): 42-48.

[58] Krishnappa PB, Badalamoole V. Karaya gum-graft-poly(2-(dimethylamino)ethyl methacrylate) gel: an efficient adsorbent for removal of ionic dyes from water. Int. J. Bio. Macromol. 2019; 122: 997-1007. 